\title{
Sistema de Gestão Integrado de Qualidade e Ambiental para Implantação de Equipamentos Facilitadores em cavernas turísticas
}

\section{Integrated Quality and Environmental Management System for the Implementation of Facilitating Equipment in touristic caves}

\author{
Blanche Sousa Levenhagen, Heros Augusto Santos Lobo
}

RESUMO: Este artigo traz os principais resultados da dissertação de mestrado que analisou o documento técnico denominado Projeto Conceitual para Equipamentos Facilitadores em Cavernas Turísticas (PC). O PC foi um desdobramento dos Planos de Manejo Espeleológico (PMEs), cujo objetivo foi estabelecer procedimentos para instalação de equipamentos facilitadores (pontes, escadas, passarelas etc.). A pesquisa de mestrado identificou as lacunas que poderiam inviabilizar a aplicação do PC e, consequentemente, a implantação dos PMEs, bem como propôs estratégias para preencher as lacunas, através da mudança de concepção da construção do PC e a instrumentalização de um Sistema de Gestão Integrado para Implantação de Equipamentos Facilitadores em Cavernas Turísticas em Unidades de Conservação (SGI-IEF). O SGI-IEF consolidou, em formato semelhante ao preconizado nas normas técnicas ABNT ISO 9001 e 14001, a nova concepção do PC baseada no manejo adaptativo. O SGI-IEF é um produto inédito no que tange à gestão de cavernas turísticas, com potencial para influenciar políticas públicas para o manejo de cavernas turísticas em unidades de conservação sob a ótica dos sistemas de gestão de qualidade e ambiental. Este artigo descreve como o SGI-IEF foi construído e apresenta o sistema na íntegra.

PALAVRAS CHAVE: Espeleoturismo; Conservação; Ecologia; Caverna; Plano de Manejo Espeleológico. 
ABSTRACT: This article presents the main results of the master dissertation that analyzed the technical document called Conceptual Project for Facilitating Equipment in Tourist Caves (CP). The CP was an unfolding of the Speleological Management Plans (SMP), whose objective was to establish procedures for the installation of facilitation equipment (bridges, stairs, walkways, etc.). The master's research identified the shortcomings that could make the application of the CP and, consequently, the implementation of SMP impossible, as well as proposed strategies to fill the gaps by changing the design of the CP construction and the construction of an Integrated Management System for Implementation of Facilitating Equipment in Tourist Caves in Conservation Units (IMS-IFE). The IMS-IFE consolidated, in a format similar to that recommended in the technical standards ABNT ISO 9001 and 14001, the new CP design based on adaptive management. The IMS-IFE is an unprecedented product for the management of tourist caves, with potential to influence public policies for the management of tourist caves in conservation units from the point of view of quality and environmental management systems. This article describes how the IMS-IFE was built and presents the system in its entirety.

KEYWORDS: Speleotourism; Conservation; Ecology; Cave; Speleological Management Plan.

\section{Introdução}

As cavernas são patrimônio da União, conforme estabelece o inciso $X$ do art. 20 da Constituição Federal (BRASIL, 1988) e a possibilidade do uso desse Patrimônio tem amparo legal no art. 1으 do Decreto $\mathrm{n}^{\circ}$ 99.556/1990. Elas constituem um ambiente único, formadas pelo resultado de processos de intemperismo químico e físico de centenas de milhares de anos, além de abrigarem espécies endêmicas do ambiente cavernícola (TRAJANO et al., 2006; SÃO PAULO, 2014; FERREIRA et al. 2018; GARCIA et al. 2018). De acordo com Silvério (2014), as cavernas são espaços singulares e oferecem oportunidades para educação ambiental, recreação e ciência, mas que possuem resiliência baixa ou inexistente e, dificilmente, o ambiente cavernícola se recupera sozinho em uma escala de tempo humana. Diversos trabalhos (e.g. FORD; WILLIANS, 1989; GILLIESON, 1996; BOGGIANI et al., 2007) afirmam que o uso público de cavernas pelo turismo requer o manejo adequado, visto que é uma atividade tão impactante quanto qualquer outro empreendimento e que pode causar impactos negativos com danos relevantes ao ecossistema cavernícola.

Apesar da importância e fragilidade das cavernas, existem inúmeros exemplos de uso inadequado das cavernas que resultaram em degradações irreversíveis e até a destruição parcial das mesmas, tais como a caverna do Diabo (Eldorado, SP) e a gruta de Maquiné (Cordisburgo, MG) (BOGGIANI et al., 2007). Conforme Marra (2001) os impactos podem ser reduzidos e temporários, mas também podem ser irreversíveis, dependendo do grau de interferência no ambiente.

Em resposta a esta degradação, a Resolução CONAMA no 347/2004 propôs os instrumentos de gestão ambiental do patrimônio espeleológico, visando o uso sustentável e a melhoria contínua da qualidade de vida das 
populações residentes no entorno de cavidades naturais subterrâneas, bem como a necessidade de se instituir procedimentos de monitoramento e controle ambiental, visando evitar e/ou minimizar a degradação e a destruição de cavidades naturais subterrâneas e outros ecossistemas a elas associados (BRASIL, 2004). Essa Resolução também consolidou o conceito de Plano de Manejo Espeleológico (PMEs) e a obrigatoriedade de sua elaboração e aprovação pelo órgão ambiental para os empreendimentos ou atividades turísticas, religiosas ou culturais em cavernas.

Neste contexto, o Vale do Ribeira, no Sul do Estado de São Paulo, possui um conjunto de Unidades de Conservação (UC) reconhecidas como sítios do Patrimônio Mundial Natural, que abrigam uma das mais expressivas áreas cársticas brasileiras, a qual é dotada de cavernas e feições geomorfológicas únicas (KARMANN; SANCHEZ, 1979; KARMANN; FERRARI, 2002; SALLUN FILHO et al., 2008, FERREIRA et al. 2018; GARCIA et al. 2018).

Dentre estas UCs, cuja gestão é de responsabilidade da Fundação Florestal do Estado de São Paulo, estão o Parque Estadual Intervales (PEI), - Parque Estadual Turístico do Alto Ribeira (PETAR), o Parque Estadual da Caverna do Diabo (PECD) e o Parque Estadual do Rio Turvo (PERT). Com exceção do PERT, os demais parques possuem um histórico antigo de uso público de algumas de suas cavernas (BORSANELLI; LOBO, 2015).

Em 2008, a falta dos PMEs nas cavernas com uso público consolidado e o não atendimento à Resolução CONAMA 347/2004 culminou na ação civil pública no 2008.61.04.000728-5, que embargou a visitação na Caverna do Diabo, entre 20 de fevereiro e 19 de abril deste mesmo ano. A ação civil pública se estendeu para algumas cavernas do PEI, PETAR e PERT. Quatro meses após a suspensão da visitação, algumas cavernas foram reabertas por meio de um TAC (Termo de Ajustamento de Conduta) e o turismo retomado com o uso de um Plano Emergencial. Este Plano também indeferiu a visitação em diversas cavernas e, para as que tiveram a visitação deferida, o fluxo de visitantes foi drasticamente reduzido. Essa redução afetou diretamente a população do entorno e a economia de alguns bairros. Neste mesmo TAC firmou-se o compromisso de elaboração e implantação dos Planos de Manejo Espeleológico por parte da Fundação Florestal do Estado de São Paulo (SÃO PAULO, 2014a, b, c, d).

Buscando subsídios técnicos para elencar materiais apropriados para as cavernas, em julho de 2015, a Fundação Florestal contratou a empresa Ecobio Consultoria e Assessoria Sócio Ambiental Ltda. ME, cuja primeira autora deste artigo é sócia, para sistematizar estudos e produzir documentos que subsidiassem a implantação de equipamentos facilitadores no interior de cavernas objeto dos PMEs. O produto desta contratação foi nomeado de Projeto Conceitual (PC).

A proposta do PC foi buscar e organizar informações para subsidiar a escolha dos tipos de materiais e formatos de equipamentos facilitadores que atendessem as premissas estabelecidas nos PMEs, que são: a) material inerte em relação ao ambiente cavernícola; b) leiaute que produza menor impacto físico, biológico e visual às cavernas; c) monitoramento dos 
equipamentos facilitadores frente ao ambiente cavernícola e em relação à segurança dos visitantes; e d) um plano de contingência para a caverna (SÃ̃ PAULO, 2014a; ECOBIO; SÃO PAULO, 2015).

Entretanto, a Ecobio expandiu os objetivos iniciais do PC e trouxe uma nova concepção a este documento, ou seja, com base no produto contratado pela Fundação Florestal propôs-se o estabelecimento de um protocolo que, de forma documentada, permitisse à FF acompanhar, monitorar, deferir e fiscalizar cada etapa do processo de instalação dos equipamentos facilitadores em cavernas, contemplando, inclusive, as especificidades de cada cavidade natural (ECOBIO; SÃO PAULO, 2015).

Este artigo traz os principais resultados da pesquisa que analisou o PC, identificou possíveis lacunas que poderiam comprometer a sua implantação e propôs uma estratégia para preencher estas lacunas através da construção de um Sistema de Gestão Ambiental e de Qualidade para a implantação de equipamentos facilitadores em cavernas turísticas, baseado nas premissas das Normas ISO 9001 e 14001 e nos conceitos de manejo adaptativo.

\section{Procedimentos de pesquisa}

O procedimento metodológico foi a revisão bibliográfica das temáticas abrangidas pelos PMEs, associada à análise dos Programas de Gestão dos PMEs que envolvem a implantação dos equipamentos facilitadores. Também foram analisados os próprios PMEs no que tange as concepções propostas para os equipamentos facilitadores.

Contou-se ainda com informações obtidas através de participação da primeira autora em reuniões técnicas junto à Fundação Florestal para discussão e adaptação do PC a um termo de referência (TR) para a contratação de empresa especializada para a elaboração de um primeiro projeto executivo para instalação de equipamentos facilitadores em uma caverna. Nestas reuniões observaram-se as dificuldades da FF em configurar o PC dentro das normativas de TR da instituição.

Também foram feitas visitas técnicas em cavernas para a avaliação funcional dos equipamentos facilitadores existentes, bem como entrevistas (conversas informais) com monitores ambientais, nos Parques Estaduais Intervales (PEI), Turístico do Alto Ribeira (PETAR), além do gestor do Parque Estadual do Rio Turvo (PERT). O enfoque foi nos atuais procedimentos de instalação, monitoramento e manutenção dos equipamentos facilitadores existentes. A partir destas informações identificaram-se os principais entraves para a implantação do PC.

Para estabelecer as estratégias de preenchimento das lacunas do PC fizeram-se ensaios e reflexões sobre as estratégias de estruturação de um sistema de gestão que atendesse a realidade administrativa, financeira, logística e operacional de uma Unidade de Conservação tendo como base as Normas ABNT ISO 9001 e 14001. Esta concepção foi a base da construção do denominado Sistema de Gestão Integrado para Implantação 
de Equipamentos Facilitadores em Cavernas Turísticas em Unidades de Conservação (SGI-IEF), que se seguiu por etapas.

A primeira etapa foi revisar e aprofundar o termo "material inerte", que no PC é denominado de "grau de inertiblidade". A segunda etapa foi construir uma concepção de ferramenta para o armazenamento e organização das informações coletadas para a seleção dos materiais, que possibilitasse a gestão destas informações considerando as premissas e conceitos das Normas ISO 9001 e 14001.

A terceira etapa foi contextualizar a abrangência das atividades relacionadas com todas as etapas da implantação de equipamentos facilitadores (elaboração de projeto, implantação, manutenção e monitoramento) a um sistema de gestão que possibilitasse a melhoria contínua. Nesta etapa utilizaram-se as concepções de cadeias produtivas.

A quarta etapa foi à construção do SGI-IEF, a partir do modelo de estabelecimento de requisitos mínimos para um sistema de gestão de qualidade e ambiental.

\section{Resultados}

\section{Análise do objeto da pesquisa: O Projeto Conceitual}

O PC foi elaborado considerando seu papel de documento orientador para o desenvolvimento de todas as etapas necessárias para a implantação dos equipamentos facilitadores conforme as premissas dos PMEs. Para tanto, este foi configurado em um formato de protocolo que estabelece, detalhadamente, os procedimentos para o desenvolvimento de cada etapa do processo de implantação dos equipamentos facilitadores em cavernas, desde a elaboração de planta e memorial descritivo da caverna, até a implantação e monitoramento de cada equipamento facilitador (ECOBIO; SÃO PAULO, 2015).

Além de determinar o método a ser utilizado em cada etapa, o PC é inflexível e não possibilita adaptações que, por ventura, possam obter melhores resultados com menor custo. Como exemplo, aponta-se a exigência para a planta da caverna e o memorial descritivo, que é uma topografia 5D com uma distância de $2,00 \mathrm{~m}$ para cada visada.

O PC ainda propôs o preenchimento de seis matrizes para subsidiar a tomada de decisão quanto ao caminhamento na caverna. As matrizes abordam um número limitado de fatores a serem analisados, e tratam das seguintes temáticas: Segurança do visitante, percepção do visitante, pontos de dispersão, preservação da caverna e plano de contingência (ECOBIO e SÃO PAULO, 2015). Seu foco foi a implantação do equipamento facilitador, bem como a inertibilidade dos materiais a serem utilizados.

Apesar desta característica engessada e inflexível, este protocolo trouxe diversas inovações conceituais e metodológicas para a implantação dos equipamentos facilitadores. Entre elas, expôs um novo olhar para a discussão do material inerte, e propôs um método que, amparado no ciclo do PDCA (Plan, Do, Check e Act = Planejar, Fazer, Verificar e Agir), o qual visa 
garantir o registro detalhado de cada etapa da implantação dos equipamentos facilitadores. Ainda vislumbra a implantação do processo de melhoria contínua para as etapas de instalação, monitoramento e manutenção dos equipamentos facilitadores, bem como considera a organização das informações em um banco de dados.

\section{Lacunas do Projeto Conceitual}

As características inflexíveis e engessadas do PC tornaram sua implantação inviável ou incompatível com a realidade de uma unidade de conservação. Assim, foi necessário identificar os elementos que causaram tamanha rigidez. Esta estava associada a concepção do PC, que considerou o equipamento facilitador como um produto final e, que apesar de trazer diversas inovações conceituais e priorizar a excelência construtiva e de monitoramento de cada equipamento, não conseguiu inserir as inovações propostas no contexto da gestão de uma caverna turística inserida em uma unidade de conservação e no atendimento as premissas dos PMEs.

Para os PMEs, o produto final é o turismo em cavernas com os seguintes objetivos: mínimo impacto à caverna e a ecologia cavernícola, excelência na experiência do visitante quanto à segurança, contato com o meio e educação ambiental e, fonte de renda para a região em um contexto de sustentabilidade socioambiental. Os equipamentos facilitadores são parte deste produto (SÃO PAULO, 2014a, b, c, d).

Assim, foi necessário rever a concepção do $P C$, e iniciou-se esta releitura a partir da temática que culminou a elaboração do PC - o termo "material inerte" (ECOBIO; SÃO PAULO, 2015). Na sequência buscaram-se estratégias para atender a demanda do produto final proposto pelos PMEs, mantendo os avanços conceituais trazidos pelo PC.

\section{Preenchendo as lacunas e construindo o SGI-IEF}

O PC abordou a questão da inertibilidade dos materiais em caverna com a proposta de mensuração de deterioração dos respectivos materiais em uma escala específica denominada "Grau de Inertibilidade" (ECOBIO; SÃO PAULO, 2015). Conforme Isaia (2017), a maioria dos materiais em contato com o meio ambiente forma um sistema instável, o que gera um potencial de reatividade, porém não determina a velocidade com que ela possa ocorrer e como ocorrerá. Por não existirem, na literatura, estudos específicos sobre a deterioração de materiais em ambiente cavernícola, o estabelecimento de uma escala com base em ensaios laboratoriais ou fichas técnicas de materiais utilizados na indústria, por exemplo, poderia trazer equívocos quanto à determinação dos intervalos desta escala, bem como quanto à reatividade e aos potenciais impactos dos materiais na ecologia cavernícola. Assim, determinar um "Grau de Inertibilidade" para cada material do equipamento facilitador de cada caverna não corresponderia a uma escala confiável ou próxima a realidade das reações potenciais entre os materiais e a ecologia cavernícola. 
De acordo com um dos PMEs consultados, o do PETAR,

o controle, minimização, e eliminação dos impactos da visitação dependem de um intenso trabalho de manejo e poucas vezes respondem imediatamente as intervenções aplicadas. O uso de metas de redução surge com uma eficiente ferramenta de manejo, na qual, de acordo com o entendimento do impacto e sua gravidade, é possível estipular metas de redução a serem alcançadas em um determinado período de tempo (SÃO PAULO, 2014b, p. 142).

A abordagem utilizada pelo PC - "Grau de inertibilidade" - ainda possibilita que todo e qualquer material tenha potencialidade para ser testado e, a partir dos testes, pode-se estabelecer a utilidade deste material no ambiente cavernícola. Esta fase de "testes" pode trazer danos a ecologia cavernícola, o que torna a abordagem de "Grau de Inertibilidade" uma ferramenta de manejo ineficaz. Para tornar a seleção dos materiais bem como o método de monitoramento de sua deterioração mais restritivo, alterou-se o termo "Grau de Inertibilidade" para "material com potencial de monitoramento de inertibilidade frente ao ambiente cavernícola". Com isto, verificou-se que esta nova concepção passou a atender concomitantemente as especificações técnicas do material, as legislações vigentes e os PMEs.

Com esta nova abordagem para material inerte, foram estabelecidas as estratégias para determinar o que é um material com potencial de monitoramento. Entretanto, tais estratégias foram determinadas sob uma nova ótica, onde o equipamento facilitador estava inserido em uma cadeia produtiva. Contudo, por tratar-se de um contexto de área natural protegida, a concepção da cadeia produtiva deveria abranger os objetivos preconizados no SNUC (BRASIL, 2000). Assim, utilizar conceitos de cadeias produtivas aplicadas em indústrias seria um equívoco. Optou-se pela concepção de Ecologia Industrial, visto que essa abordagem possibilita visualizar as organizações como ecossistemas industriais sustentados por ecossistemas naturais, que são os produtores de matéria-prima (KRAVCHENKO et al, 2016).

A característica apontada por Kravchenko et al.(2016) associada à definição de Almeida e Giannetti (2012), que afirmam que para a Ecologia Industrial cada indústria e sua estrutura são consideradas como um sistema produtivo e também como um subsistema da biosfera, e que as indústrias podem ser vistas como organizações de fluxos de matéria, energia e informação e sua evolução deve ser compatível com o funcionamento dos ecossistemas onde estão inseridas, se enquadram e corroboram com as premissas de gestão dos PMEs.

Para estruturar e ilustrar o trecho da cadeia produtiva do turismo em cavernas inseridas em UCs que trata das ações vinculadas à implantação e monitoramento dos equipamentos facilitadores, optou-se pelo modelo da gestão de demanda proposta por Croxton et al. (2008). Este modelo mostra 
a gestão da demanda no plano estratégico e operacional, bem como permite que a esta seja compreendida a partir de todas as suas interfaces, oferecendo, assim, uma visão integrada do relacionamento entre todos os processos, funções organizacionais e elos-chave da cadeia produtiva.

Os processos estratégicos foram então identificados e para estes, foram determinadas as metas necessárias para atingir a eficácia do produto deste trecho da cadeia produtiva. Para os processos operacionais, foram considerados os procedimentos necessários à viabilização dos processos estratégicos. Como interface entre os processos estão os subsistemas de gestão (CROXTON et al., 2008). A Figura 1 apresenta o modelo de gestão proposto para a cadeia produtiva que pode envolver a implantação dos equipamentos facilitadores.

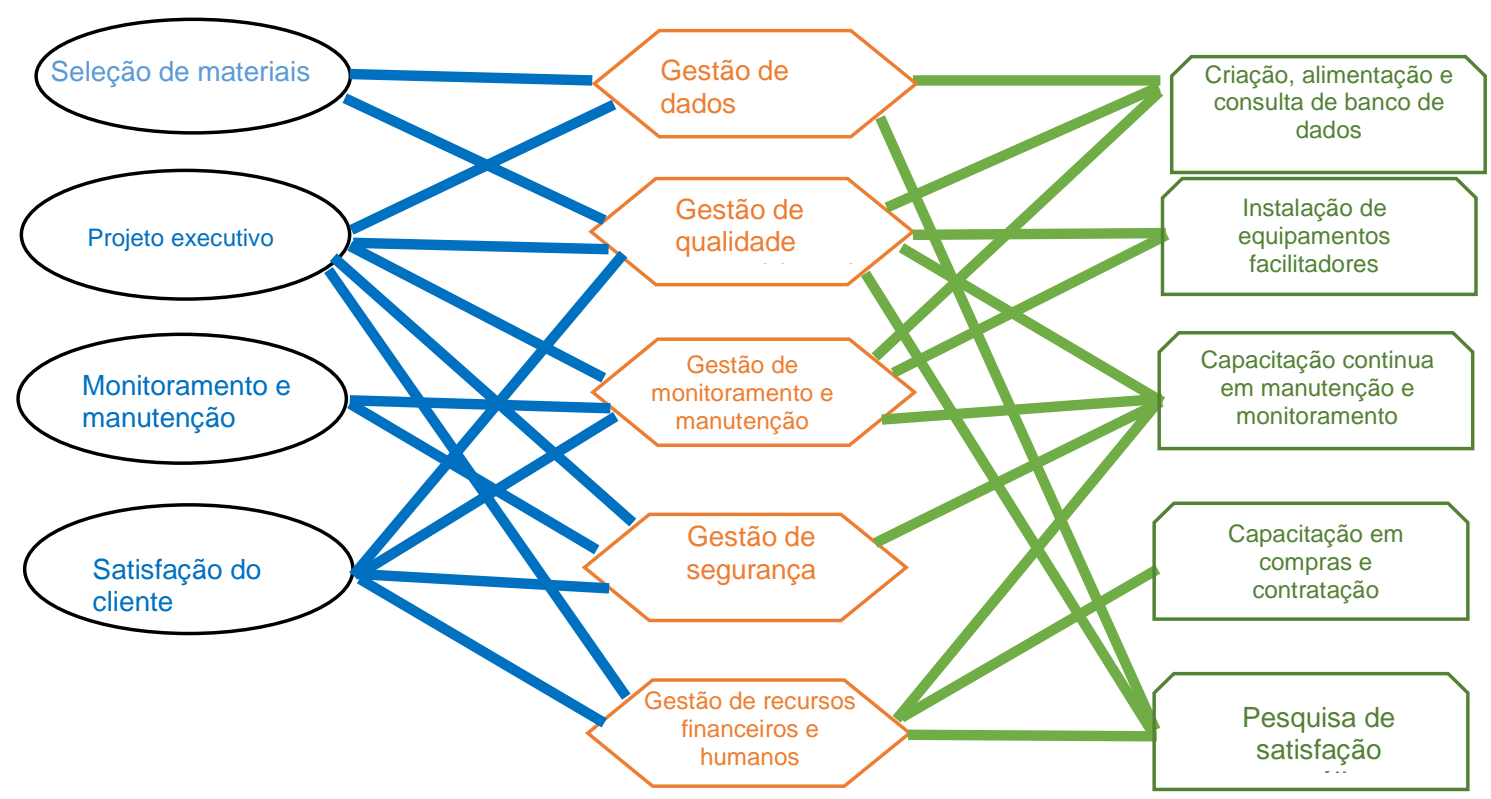

Figura 1: Adaptação de modelo de gestão de demanda de Croxton et al. (2008) para o trecho da cadeia produtiva dos equipamentos facilitadores. Fonte: elaborado pelos autores.

Figure 1: Adaptation of the demand management model by Croxton et al. (2008) for the stretch of the productive chain of facilitating equipment. Source: the authors.

A partir da releitura do $\mathrm{PC}$, que inseriu a implantação dos equipamentos facilitadores em uma cadeia produtiva, identificou-se a necessidade de estabelecer um método de gestão que compactuasse com a proposta de melhoria continua explicitada no PC e nos PMEs (SÃO PAULO, 2014a, b, c, d, ECOBIO; SÃO PAULO, 2015).

O ciclo PDCA viabiliza a melhoria continua a partir do monitoramento e análise de dados, e ações de melhoria a partir dos resultados das análises (ABNT ISO 9001, 2015 e ABNT ISO 14001, 2015). Essa sistemática corrobora os objetivos de área protegidas estabelecidos pela IUCN, no que tange a 
operar sob a orientação de um plano de manejo e de um programa de monitoramento e avaliação que deem apoio à gestão adaptativa; possuir um sistema de governança claro, eficaz e equitativo (BORRINI-FEYERABEND et al., 2017).

Assim, optou-se por considerar como ferramenta de gestão da cadeia produtiva as concepções das Normas ISO 9001 e 14001. Em ambas as normas a política de qualidade e ambiental tem o propósito de estabelecer, implementar e manter procedimentos que sejam apropriados ao contexto da atividade e do local, de prover uma estrutura para o estabelecimento dos objetivos da qualidade e ambientais, de se comprometer em atender requisitos aplicáveis à atividade e com a melhoria contínua do sistema de gestão da qualidade e ambiental (ABNT, 2015a, b). Essas premissas corroboram os PMEs, com o PC aprovado pela Fundação Florestal, com o SNUC (BRASIL, 2000) e com os objetivos de áreas protegidas estabelecidos pela IUCN (BORRINI-FEYERABEND et al., 2017). Sendo a definição da política de qualidade e ambiental um requisito mandatário das normas ISO 9001 e 14001 (ABNT, 2015a, b), fez-se necessário estabelecer a política para a base da gestão da cadeia produtiva. Identificou-se que diversas linhas de ação dos Programas de Gestão dos PMEs estavam alinhadas com alguns os requisitos das Normas ISO. Trechos do Programa de Gestão do PME do PERT que evidenciam este alinhamento são apresentados no Quadro 1.

Quadro 1: Trechos do Programa de gestão do PME do PERT que estão alinhados aos requisitos da Normas ISO 9001 e 14001 e Norma ISO 26000

Frame 1: Excerpts from the PERT PME Management Program that are in line with the requirements of ISO 9001 and 14001 and ISO 26000

\section{TRECHO DO PME}

Pagina 117 - "Devem ser aperfeiçoadas as medidas e ações voltadas à minimização de impactos da visitação e a proteção efetiva do ambiente subterrâneo em um processo contínuo e permanente, e levando-se em conta o papel educador e gerador de oportunidades de trabalho e renda, fazendo que a gruta seja vista como uma das alternativas ao desenvolvimento socioeconômico da comunidade local'. ${ }^{1}$

Página 126 - "Realizar estudos de demanda e satisfação dos usuários, ${ }^{1}$

Outro importante subsídio à gestão é o grau de satisfação dos visitantes em relação ao roteiro conhecido e à experiência vivenciada. Diversos aspectos interferem nos resultados desta análise, como o tempo despendido no roteiro, o nível de conhecimento do monitor, o direcionamento do público em função de seus aspectos motivadores básicos - aventura, contemplação etc., e a segurança percebida, entre outros."

\section{CORRELAÇÃO COM AS NORMAS}

Alinhamento com a ISO $14001^{3}$ e $26000^{4}$ -

Preocupação com a mitigação de impactos ambientais, melhoria contínua do processo de mitigação dos impactos, e responsabilidade social com 0 desenvolvimento econômico da comunidade local.

Alinhamento com a ISO 90012 Preocupação com a satisfação do cliente, visto que o produto em questão é o roteiro conhecido e a vivência do turista. 
...continuação.

\begin{tabular}{l}
\hline TRECHO DO PME \\
\hline Pagina 128 - "Promover processos de \\
formação continuada do corpo funcional do \\
Parque"1
\end{tabular}

CORRELAÇÃO COM AS NORMAS

Alinhamento com a ISO 90012 -

Preocupação em assegurar que as responsabilidades e autoridades para papéis pertinentes sejam atribuídas, comunicadas e entendidas, visando a integridade do sistema de gestão da qualidade.

Página 129 - "Implantar um sistema de gestão de riscos em cavernas (Plano de Contingência e Riscos)"1

Página $129 \quad$ - $\quad$ "Implantar roteiros
espeleoturísticos de forma escalonada"1

Alinhamento com a ISO $9001^{2}$ -

Preocupação em implantar ações preventivas através de coleta, armazenamento e análise de dados.

Alinhamento com a ISO $14001^{3}$ Avaliação de aspectos e impactos ambientais considerando os riscos e oportunidades que precisam ser abordados.

Página 129 - "Promover processos de formação continuada para os monitores ambientais que incluam monitores regionais"1

Alinhamento com a ISO $26000^{4}$ Preocupação com o fomento ao desenvolvimento sustentável da comunidade local.

Página 132 - "O Processo de Monitoramento e o Ciclo de Avaliação

Grande parte dos indicadores de impactos selecionados podem ser aplicados, futuramente, pelos próprios monitores ambientais locais que atuam no PETAR, espeleólogos e voluntários, contudo estes devem ser capacitados para tal, evitando com isso subjetividade na leitura dos indicadores e erros de interpretação"1

Página 142 - Quanto ao Monitoramento de indicadores definidos nos PME

"Através da comparação entre os índices observados no monitoramento e os determinados pelo padrão, será possível verificar a não conformidade de um indicador específico, ou seja, que se encontra fora do padrão estabelecido e, assim, determinar ações de manejo a fim de reverter o quadro de impactos."1

Alinhamento com a ISO $9001^{2}$ e $14001^{3}-$ Preocupação com a identificação e monitoramento de aspectos e impactos ambientais e preocupação em assegurar que as responsabilidades e autoridades para papéis pertinentes sejam atribuídas, comunicadas e entendidas, visando a integridade do sistema de gestão da qualidade.

Alinhamento com a ISO $9001^{2}$ e $14001^{3}$ Conforme item 10.2 de ambas as Norma: Ao ocorrer uma não conformidade, a organização deve: a) reagir à não conformidade e, como aplicável: 1) tomar ação para controlá-la e corrigi-la;2) lidar com as consequências, incluindo mitigar impactos ambientais adversos; b) avaliar a necessidade de uma ação para eliminar as causas da não conformidade, a fim de que ela não se repita ou ocorra em outro lugar: 1) analisando criticamente a não conformidade; 2) determinando as causas da não conformidade; 3) determinando se não conformidades similares existem ou se poderiam potencialmente ocorrer; c) implementar qualquer ação necessária;d) analisar criticamente a eficácia de qualquer ação corretiva tomada;e) realizar mudanças no sistema de gestão ambiental, se necessário.

As ações corretivas devem ser apropriadas à significância dos efeitos das não conformidades encontradas, incluindo o(s) impacto(s) ambiental(is).

Continua... 
.continuação.

\begin{tabular}{|c|c|}
\hline TRECHO DO PME & CORRELAÇÃO COM AS NORMAS \\
\hline $\begin{array}{l}\text { Página } 142 \text { - Sobre gestão do monitoramento } \\
\text { "Os padrões de monitoramento a serem } \\
\text { estabelecidos são resultados de uma análise } \\
\text { primária detalhada da caverna e, por isso, } \\
\text { muito particulares para a situação encontrada, } \\
\text { devendo assim ser determinados e alterados } \\
\text { pelos responsáveis do monitoramento na UC"1 }\end{array}$ & $\begin{array}{l}\text { Alinhamento com a ISO } 9001^{2} \text { e } 14001^{3}- \\
\text { Conforme item 6.2.2. de ambas as } \\
\text { normas: Ao planejar como alcançar seus } \\
\text { objetivos da qualidade, a organização } \\
\text { deve determinar: a) o que será feito; b) } \\
\text { quais recursos serão requeridos; c) quem } \\
\text { será responsável; d) quando isso será } \\
\text { concluído; e) como os resultados serão } \\
\text { avaliados. }\end{array}$ \\
\hline $\begin{array}{l}\text { Página } 142 \text { - Metas de redução } \\
\text { "O controle, minimização, e eliminação dos } \\
\text { impactos da visitação dependem de um } \\
\text { intenso trabalho de manejo e poucas vezes } \\
\text { respondem imediatamente as intervenções } \\
\text { aplicadas. O uso de metas de redução surge } \\
\text { com uma eficiente ferramenta de manejo, na } \\
\text { qual, de acordo com o entendimento do } \\
\text { impacto e sua gravidade, é possível estipular } \\
\text { metas de redução a serem alcançadas em um } \\
\text { determinado período de tempo".1 }\end{array}$ & $\begin{array}{l}\text { Alinhamento com a ISO } 14001 .^{3} \\
\text { Conforme item } 3.2 .7 \text {-: uso de processos, } \\
\text { práticas, técnicas, materiais, produtos, } \\
\text { serviços ou energia para evitar, reduzir ou } \\
\text { controlar (separadamente ou em conjunto) } \\
\text { a geração, emissão ou descarga de } \\
\text { qualquer tipo de poluente ou rejeito, a fim } \\
\text { de reduzir os impactos ambientais } \\
\text { adversos. } \\
\text { A prevenção da poluição pode incluir } \\
\text { redução ou eliminação da fonte; } \\
\text { modificações no processo, produto ou } \\
\text { serviço; uso eficiente de recursos; } \\
\text { substituição de material e de energia; } \\
\text { reuso; recuperação; reciclagem; } \\
\text { regeneração; ou tratamento. }\end{array}$ \\
\hline
\end{tabular}

Fonte: ' São Paulo (2014c), ${ }^{2}$ ABNT (2015 a), ${ }^{3}$ ABNT (2015b) e ${ }^{4}$ ABNT (2010), adaptado pelos autores. Source: 'São Paulo (2014c), ${ }^{2}$ ABNT (2015), ${ }^{3}$ ABNT (2015) e ${ }^{4}$ ABNT (2010), adapted by the authors.

Por conta deste alinhamento, estabeleceu-se que a política de qualidade e ambiental são os Programas de Gestão dos PMEs. O resultado final desta pesquisa foi a consolidação de uma ferramenta em formato semelhante ao preconizado em uma Norma ISO que uniu as premissas de unidades de conservação do SNUC (BRASIL, 2000) e da IUCN (BORRINIFEYERABEND et al., 2017) com metodologias de gestão de qualidade e ambiental utilizadas em setores privados de indústrias e serviços. A união destas frentes e sua adaptação para 0 atendimento aos requisitos dos Programas de Gestão dos PMEs é inédita e inovadora. Atribui-se ainda a esta iniciativa um grande potencial para influenciar políticas públicas no que tange a gestão de cavernas turísticas em unidades de conservação. O SGIIEF na íntegra está apresentado na sequência.

\section{SGI-IEF: Sistema de Gestão Integrado (Qualidade e Ambiental) - Implantação de Equipamentos Facilitadores}

\section{Definição}

O SGI-IEF é um documento norteador para o desenvolvimento de todas as etapas necessárias para atender os Programas de Gestão dos PMEs no que tange a implantação dos equipamentos facilitadores. Seu objetivo é especificar requisitos que possam garantir a gestão de qualidade e 
ambiental, considerando um ciclo de melhoria contínua, o manejo adaptativo a atendimento ao SNUC e os objetivos da IUCN para áreas protegidas.

\section{Composição}

O SGI-EF é composto por seis partes, sendo estas: a) Parte 1 Política Ambiental e de Qualidade; b) Parte 2 - Mapeamento de cadeia produtiva; c) Parte 3 - Memorial descritivo da caverna, d) Parte 4 - O projeto básico, e) Parte 5 - Gestão de dados e informações e f) Parte 6 - Sugestões de matrizes.

\subsection{Parte 1-Política Ambiental e de Qualidade}

Deve ser estabelecido a partir dos Programas de Gestão dos PMEs e abranger todo o contexto que envolve a realidade de uma unidade de conservação ou, o local onde a caverna está inserida.

\subsection{Parte 2- Mapeamento da cadeia produtiva}

O mapeamento deve ser feito considerando todos os elementos e steakholders envolvidos e deve definir o fluxo entre esses elementos, bem como seus papeis e responsabilidades na cadeia produtiva.

\subsection{Parte 3- Memorial Descritivo da Caverna}

\subsubsection{Definição}

O memorial descritivo é um documento que detalha todo o trajeto da caverna onde serão realizadas as intervenções para o turismo. Nele estão descritas e registradas as informações pormenorizadas de todos os detalhes necessários para a tomada de decisão quanto às intervenções e monitoramentos para cada trecho de cada cavidade natural, nos roteiros existentes ou propostos no PME de cada caverna. Também estão detalhadas as características e informações necessárias para a elaboração do projeto básico e projeto executivo do (s) equipamento (s) facilitador (es).

\subsubsection{Composição do memorial descritivo}

Composto por um produto em texto e um produto gráfico. Ambos os produtos devem considerar em seu desenvolvimento, no mínimo, os seguintes aspectos de tomada de decisão:

Segurança do visitante: considera a segurança do visitante frente ao percurso turístico na caverna. Considera possibilidades de: lesões, quedas, escorregamento ou outros acidentes que possam ocorrer devido à morfologia da caverna e ao tipo de visitação proposto: Neste aspecto devem ser considerados grupos de visitantes de todos os perfis.

No mínimo, ainda devem ser considerados como obstáculos, conforme Lobo et al. (2011): 
$\checkmark$ Inclinação e/ou locais lisos: Locais do conduto com inclinação acentuada e/ou lisa que podem provocar escorregamento ou falta de equilíbrio causando a queda do visitante, ou obrigando este a se apoiar nas paredes ou espeleotemas das cavernas.

$\checkmark$ Lama: Locais do conduto com lama (normalmente próximo à entrada da caverna) que podem provocar escorregamento ou falta de equilíbrio causando a queda do visitante, ou obrigando este a se apoiar nas paredes ou espeleotemas das cavernas.

$\checkmark$ Desnível: Locais do conduto que apresentam desníveis como abismos ou degraus que possam trazer risco ao visitante.

$\checkmark$ Presença de água: Locais do conduto que tenham corpos d'água que possam oferecer algum risco ao visitante, como corredeiras fortes ou rios e lagos mais profundos. Não são considerados eventos como cheias, tendo em vista a interdição da caverna para visitação em eventos como este.

$\checkmark$ Presença de estruturas: indicar a presença ou não de estrutura de apoio e se ela está sendo eficaz na função de segurança do visitante. Devem ainda ser considerados como avaliação de obstáculos:

$\checkmark$ Extensão do circuito interno: Extensão total, em metros lineares, do trajeto de visitação a ser percorrido dentro da caverna. Nos trechos onde o caminho de ida e volta se sobrepõem, a metragem deve ser considerada em ambos os sentidos do caminhamento.

$\checkmark$ Pequenas escaladas: Existência de obstáculos que precisem ser transpostos por meio de técnicas de escalada, sem uso de equipamentos específicos ou, no máximo, com instalação de cordas/cabos de apoio.

$\checkmark$ Teto baixo: Presença de trechos onde o rebaixamento do teto e/ou elevação do piso não permitam ao visitante caminhar em posição ereta;

$\checkmark$ Quebra-corpo: Presença de trechos estrangulados, entre blocos abatidos ou em condutos muito restritos.

$\checkmark$ Trechos escorregadios: Trechos de no mínimo 3m de distância, onde a instabilidade e/ou o tipo de piso ofereçam risco eminente de queda, independente da existência de corrimãos ou apoios naturais no local.

$\checkmark$ Travessia de corpos d'água: Travessia de cursos ou corpos d'água, independente da vazão do curso d'água ou distância percorrida, desde que esta seja suficiente para molhar os pés do visitante.

$\checkmark$ Trechos de natação: Travessia de cursos ou corpos d'água onde seja necessário o uso de técnicas de natação ou mesmo de travessia com apoio de cordas/cabos em trechos de profundidade insuficiente para andar. 
Percepção do visitante: locais do conduto que tragam ao visitante a sensação de estar num ambiente cavernícola pouco modificado. As sensações de exploração e aventura devem ser consideradas nesta matriz, tendo em vista que o espeleoturismo está, também, diretamente vinculado ao turismo de aventura. São considerados os mesmos obstáculos do aspecto Segurança do visitante, entretanto com a perspectiva de colocar o visitante em contato com a diversidade ambiental do ambiente cavernícola. Inclui-se aqui, no mínimo:

$\checkmark$ Presença de equipamento facilitador: indicar a presença ou não, a necessidade ou não, de equipamento facilitador. Caso o equipamento já exista, avaliar se está sendo eficaz na função de não ofuscar a paisagem.

Pontos de dispersão controlada: Os aspectos vinculados à percepção e educação ambiental, bem como a interpretação ambiental e patrimonial, em pontos de agrupamento e dispersão do grupo. Por conta desta necessidade, nesta matriz deve ser considerada a questão do espaço para grupos conforme a indicação de capacidade de carga dos PMEs para cada caverna e roteiro. No mínimo devem ser avaliados:

$\checkmark$ Detalhamento da Paisagem: Locais que estimulem a percepção e a imaginação do visitante, como formações de cavernas que possuem formas de bichos, pessoas, ou locais que possuem salões que histórias que agucem a percepção, sensações térmicas (mudança de temperatura do ambiente, corrente de vento, etc.), bem como locais propícios às explanações sobre o ambiente das cavernas, em seus diversos aspectos (geomorfológico, geológico, climático, biológico, arqueológico etc.). Cada um destes locais deve ser descrito com a devida justificativa.

$\checkmark$ "Blackout": Local propício a uma atividade comum em cavernas que é o "blackout", onde todos apagam suas luzes para ter a sensação de escuridão total.

$\checkmark$ Espaço: local que comporta o agrupamento de visitantes conforme a quantidade de pessoas por grupos indicada de capacidade de carga dos PMEs para cada caverna.

Nos pontos selecionados para a Pontos de dispersão, deve-se definir e delimitar o perímetro onde o grupo pode permanecer, bem como o caminhamento para a dispersão do grupo. Devem também conter um memorial fotográfico com a indicação das respectivas visadas em planta.

Conservação da ecologia cavernícola: trechos do conduto que apresentam características relevantes à conservação da ecologia cavernícola. Devem ser considerados, no mínimo, os seguintes aspectos:

$\checkmark$ Presença de fauna: descrever as espécies, sua ecológica e medidas mitigatórias. 
$\checkmark$ Presença de espeleotemas: descrever a geomorfologia, seu status, e medidas mitigatórias.

$\checkmark$ Presença de equipamento facilitador: indicar a presença de equipamento facilitador e se ela está sendo eficaz na função de conservação a ecologia cavernícola.

$\checkmark$ Inserção de equipamento facilitador: trechos do conduto que requerem equipamento facilitador para delimitar o caminhamento.

\subsubsection{Produto em texto}

$\mathrm{O}$ produto em texto tem o objetivo de descrever detalhadamente 0 trecho turístico da caverna. Deve fornecer informações que possibilitem a avaliação, a tomada de decisão quanto ao caminhamento e o monitoramento dos percursos frente às premissas dos PMEs. Deve ainda justificar os aspectos a serem descritos e determinar os pontos do percurso estabelecidos no PME que devem ser descritos.

No mínimo, o produto em texto deve descrever com detalhes: os espeleotemas, os riscos ao visitante, a necessidade de estrutura de segurança e/ou locomoção (caso não esteja especificado no PME), os atrativos da caverna, a presença de fauna, a litologia, os riscos ao ambiente cavernícola, a presença de corpo d'água, a presença de gotejamento, o histórico de inundação e a descrição e a justificativa de caminhamento (caso não esteja especificado no PME).

Os requisitos para elaboração do produto em texto são:

$\checkmark \mathrm{O}$ produto em texto deve trazer as informações necessárias para 0 estabelecimento da demarcação do caminhamento nas cavernas de forma justificada.

$\checkmark \mathrm{O}$ produto em texto deve ser elaborado por equipe multidisciplinar. Deve-se justificar a necessidade da formação e capacitação em espeleologia e outras áreas correlatas necessárias para a elaboração do produto em texto;

$\checkmark$ As informações do produto em texto devem ser organizadas e classificadas, no mínimo, nos temas (aspectos): Segurança do visitante, Percepção do ambiente cavernícola por parte do visitante (sensibilização ambiental, educação ambiental e interpretação ambiental e patrimonial), conservação da ecologia cavernícola e pontos de dispersão.

$\checkmark$ Sugere-se que cada conjunto de aspectos referentes a um tema deve compor uma matriz de tomada de decisão. Cada conjunto de aspectos de tomada de decisão devem ser vinculadas à planta do produto gráfico afim de se possibilitar a identificação do local que está sendo descrito.

$\checkmark O$ método de preenchimento das matrizes de tomada de decisão deve possuir um sistema de valoração que garanta a isenção de opinião pessoal do responsável pelo preenchimento da matriz. Como 
exemplo, pode-se utilizar o sistema booleano, ou seja, considerar o valor 0 para a inexistência do aspecto e o valor 1 para a existência do aspecto.

\subsubsection{Produto em gráfico}

O objetivo do produto em gráfico é fornecer uma planta detalhada da caverna que deve ser a base para a elaboração do projeto básico e projeto executivo do equipamento facilitador, considerando a legislação vigente e as premissas dos PMEs e deste Sistema de Gestão.

Os requisitos para elaboração do produto em gráfico são:

$\checkmark$ A planta da caverna deve estar em escala compatível que possibilite a visualização da configuração e estrutura do (s) percurso (s) turístico (s) conforme o PME.

$\checkmark$ A planta do percurso turístico deve estar em escala compatível e demarcar detalhadamente o percurso turístico, conforme estabelecido no PME. Deve conter estreitamentos, quebra-corpos, formações cársticas, e os demais aspectos descritos no produto em texto;

$\checkmark$ processo de mapeamento deve seguir as normas e convenções espeleométricas da SBE (Sociedade Brasileira de Espeleologia), ou outra de melhor detalhe e apuração técnica.

$\checkmark$ A planta deve utilizar, no mínimo, os métodos de Projeção Horizontal $(\mathrm{PH})$ e Desenvolvimento Linear (DL), bem como os conceitos de continuidade e descontinuidade no mapeamento espeleométrico;

$\checkmark$ Deve definir o grau de erro da topografia através de métodos reconhecidos como a graduação UIS (Union Internationale de Spéléologie) e a graduação BCRA (Bristish Cave Research Association);

$\checkmark$ percentual de erro das medidas, se houver, deve ser descrito para cada trecho;

$\checkmark$ A precisão da planta deve ser compatível com o requerido para a elaboração do projeto básico e projeto executivo do equipamento facilitador, conforme legislação vigente.

$\checkmark$ Todas as plantas devem ser apresentadas em formato editável, preferencialmente em extensões utilizadas para elaboração de projetos de construção civil;

$\checkmark$ Em caso de identificação de inconsistências entre o percurso definido no PME e a caverna, o fato deve ser informado e descrito detalhadamente ao órgão gestor;

$\checkmark$ Os pontos definidos para a implantação do equipamento facilitador, devem ser apresentados de forma ampliada, com corte vertical e horizontal e com medidas detalhadas em toda a extensão onde 0 equipamento facilitador será instalado. 
$\checkmark$ Nos pontos definidos para a implantação do equipamento facilitador, deve ser apresentado um memorial fotográfico contendo os ângulos de visadas. Devem ser estabelecidas visadas suficientes à elaboração do projeto básico e executivo do equipamento facilitador;

$\checkmark$ Para a elaboração da planta detalhada podem ser utilizadas tecnologias de varredura 3D ou similar, desde que o resultado tenha precisão necessária para a elaboração do projeto básico e executivo, conforme a legislação vigente.

\subsection{Parte 4 - O Projeto básico do equipamento facilitador}

O projeto básico é composto por um produto em texto e outro em gráfico. Os requisitos para o projeto básico são:

$\checkmark$ Todas as estruturas devem ser modulares e sua descrição no produto em texto deve ser dividida em três partes: Corpo; Revestimento e Fixação, sendo a fixação subdividida em: fixação entre módulos (fixação entre degraus, p.e.) e fixação do modulo à caverna.

$\checkmark$ Devem ser produzidas duas formas de apresentação do Projeto Básico para cada equipamento facilitador. São elas: Produto em Texto e Produto em Gráfico.

\subsubsection{Produto em texto}

É composto pela descrição detalhada de cada parte do equipamento e deve atender, no mínimo, os seguintes requisitos:

$\checkmark$ Descrição de cada parte do equipamento, detalhando as respectivas medidas e o material constituinte;

$\checkmark$ Justificativa técnica para a seleção de cada material, contendo, no mínimo: a resistência a peso e corrosão, a deterioração frente ao ambiente cavernícola, bem como mínimo impacto visual à caverna.

$\checkmark$ Apresentar norma técnica, se houver, para a seleção de cada material considerando a resistência a peso e corrosão, a deterioração frente ao ambiente cavernícola, bem como mínimo impacto visual à caverna.

$\checkmark$ Apresentar o memorial de cálculo de resistência de cada equipamento;

$\checkmark$ Apresentar a justificativa técnica para a escolha do design, material e formas de implantação, manutenção e monitoramento;

$\checkmark$ presentar capacitação necessária, equipamentos e insumos necessários para a manutenção do equipamento facilitador e suas partes;

$\checkmark$ Apresentar métodos de monitoramento do equipamento facilitador frente, no mínimo, aos aspectos do memorial descritivo;

$\checkmark$ Identificar alternativas de manutenção e monitoramento, caso estas atividades não forem executadas por monitores ambientais, 
comunidade local ou funcionários do parque. Entende-se que contratos de empresas terceirizadas para executar a manutenção e monitoramento estão sujeitos a suspensões por motivos políticos e econômicos, e na ocorrência dessa a situação os equipamentos facilitadores pode se transformar num risco para os visitantes e para a conservação da ecologia cavernícola;

$\checkmark$ Apresentar a descrição detalhada do processo de implantação de cada equipamento facilitador, contendo, no mínimo: cronograma de implantação, capacitação necessária para a implantação, número de profissionais envolvidos, bem como suas respectivas funções, equipamentos necessários para a implantação, tipo, quantidade e destino de resíduo proveniente da implantação, se houver;

$\checkmark$ Apresentar descrição detalhada dos processos de avaliação (verificação) da estabilidade do equipamento facilitador, bem como das técnicas de manutenção, contendo no mínimo: os indicadores (locais e aspectos a serem verificados) e a periodicidade de verificação, justificativa técnica de cada indicador, técnicas de verificação, indicar e detalhar procedimentos de manutenção, periodicidade de manutenção.

\subsubsection{Produto em Gráfico}

É o desenho técnico de cada equipamento elaborado em sobreposição a planta do memorial descritivo e em conformidade com a legislação vigente para Projeto Básico.

Os requisitos do produto em gráfico são no mínimo:

$\checkmark$ desenho técnico deve estar em formato digital editável e em escala compatível;

$\checkmark$ desenho técnico em formato impresso deve estar em escala compatível;

$\checkmark$ Os desenhos técnicos devem seguir os critérios nas Normas ABNT.

\subsection{Parte 5 - Gestão de dados e informações}

O objetivo é a gestão da cadeia produtiva gerada pela implantação dos equipamentos facilitadores, a partir da coleta, armazenamento, organização e análise de dados e informações geradas em todos os processos desta cadeia produtiva.

Os requisitos mínimos são:

$\checkmark$ Definição e mapeamento da cadeia produtiva;

$\checkmark$ Definição das responsabilidades e das capacitações necessárias para cada etapa da cadeia produtiva;

$\checkmark$ Estabelecimento de um sistema de gerenciamento de dados que garanta a rastreabilidade e a reprodutibilidade da cadeia produtiva; 
$\checkmark$ Estabelecimento de um sistema de gerenciamento de dados que garanta o armazenamento dos dados de todas as etapas da cadeia produtiva e que possibilite o cruzamento e análises diversas, proporcionando a melhoria contínua e a utilização desta base para estudos diversos, inclusive acadêmicos.

\subsection{Parte 6 - Sugestões de matrizes}

Este sistema traz sugestão de matrizes de coleta e organização de dados nas Figuras 3 e 4. Estas matrizes são básicas e devem ser complementadas e/ou modificadas conforme a necessidade de cada percurso turístico e caverna, bem como cada cadeia produtiva.

\subsubsection{Organização das matrizes}

As matrizes foram elaboradas com o intuito de coletar e organizar as informações mínimas para a tomada das decisões com relação a design, material, formas de instalação, manutenção e monitoramento relativos à implantação dos equipamentos nas cavernas.

No formato sugerido, cada matriz refere-se à ao local e tipo de equipamento facilitador. $E$ cada submatriz refere-se a uma parte do equipamento. A Figura 2 mostra como as matrizes estão organizadas.

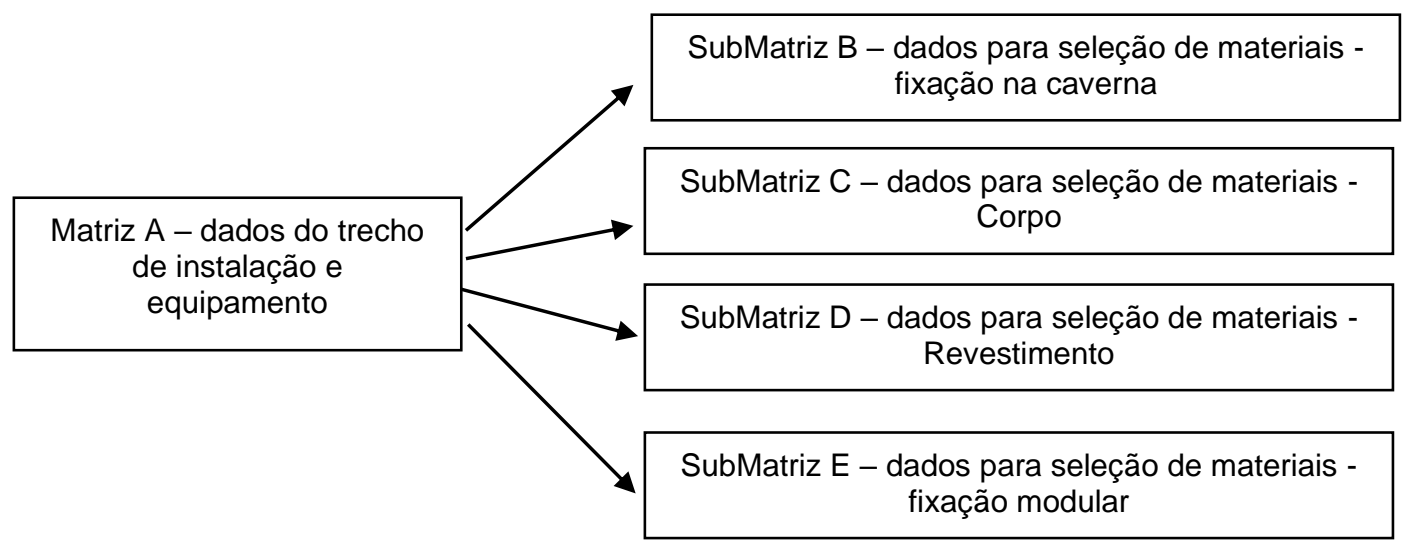

Figura 2: Relacionamento entre a Matriz A e as demais submatrizes.

Fonte: elaborado pelos autores.

Figure 2: Relationship between Matrix A and the other sub-matrices.

Source: the authors.

A Figura 3 traz uma proposta para as informações da Matriz A e a Figura 4 mostra a proposta para o formato e organização das informações das demais submatrizes. 


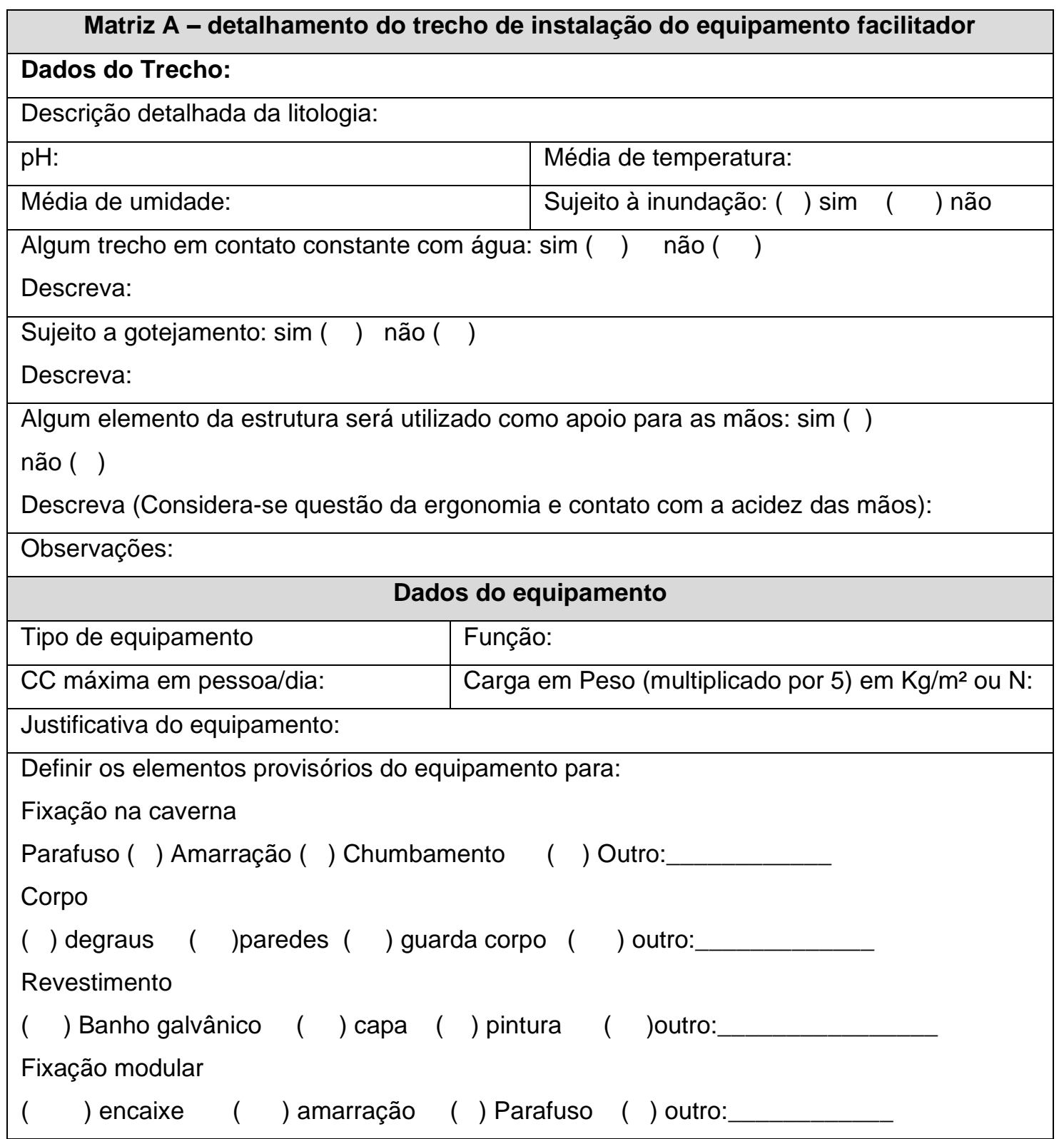

Figura 3: Modelo proposta para a Matriz A. Fonte: elaborado pelos autores.

Figure 3:Model proposed for Matrix A. Source: the authors.

A submatriz da Figura 4 é composta por perguntas que irão direcionar a tomada de decisão quanto aos materiais utilizados. Estas perguntas podem ser alteradas, assim como podem ser adicionadas outras para cada percurso turístico e cada caverna. É imprescindível que se mantenha o atendimento aos PMEs e a legislação vigente para projeto básico. 


\begin{tabular}{|c|c|c|}
\hline \multicolumn{3}{|l|}{$\begin{array}{l}\text { Elemento: fixação modular (p.e.) } \\
\text { Tipo: Parafuso (p.e.) }\end{array}$} \\
\hline \multicolumn{3}{|c|}{ PARTE 01 - LISTA DE MATERIAIS PASSÍVEIS DE USO } \\
\hline \multicolumn{3}{|c|}{$\begin{array}{l}\text { Materiais indicados para avaliação: ( ) Rocha ( )Madeira ( ) Concreto Armado ( X) } \\
\text { Aço carbono ( X Aço inoxidável ( ) Composto polimérico reforçado com fibra ( ) Outro } \\
\text { ( ) } \\
\text { Descrição do outro: }\end{array}$} \\
\hline \multicolumn{3}{|c|}{$\begin{array}{l}\begin{array}{l}\text { Para os materiais selecionados acima devem ser respondidos os seguintes } \\
\text { questionamentos: }\end{array} \\
\end{array}$} \\
\hline \multicolumn{3}{|c|}{ SEGURANÇA DO VISITANTE } \\
\hline & $\begin{array}{c}\text { Aço } \\
\text { Carbono }\end{array}$ & $\begin{array}{c}\text { Aço } \\
\text { Inoxidável }\end{array}$ \\
\hline \multicolumn{3}{|l|}{$\begin{array}{l}\text { Suporta carga especificada na ficha técnica? } \\
\text { (Apresentar memorial de cálculo com base em norma técnica } \\
\text { de ensaio) }\end{array}$} \\
\hline \multicolumn{3}{|l|}{$\begin{array}{l}\text { Qual o tempo estimado de corrosão ou deterioração do } \\
\text { material no ambiente apresentado na ficha técnica? } \\
\text { (Apresentar memorial de cálculo com base em norma técnica) }\end{array}$} \\
\hline \multirow{2}{*}{\multicolumn{3}{|c|}{\begin{tabular}{l|l}
$\begin{array}{l}\text { Qual a melhor especificação do material que deve ser usado? } \\
\text { (Apresentar justificativa com base em norma técnica) }\end{array}$ & \\
CONSERVACÃO DA ECOLOGIA DA CAVERNA
\end{tabular}}} \\
\hline & & \\
\hline \multicolumn{3}{|l|}{$\begin{array}{l}\text { O material está sujeito à corrosão no ambiente da caverna? } \\
\text { (Apresentar justificativa com base em norma técnica) }\end{array}$} \\
\hline \multicolumn{3}{|l|}{$\begin{array}{l}\text { Quais elementos são liberados durante a deterioração do } \\
\text { material? } \\
\text { (Apresentar justificativa com base em norma técnica) }\end{array}$} \\
\hline \multicolumn{3}{|l|}{$\begin{array}{l}\text { Qual o período estimado para iniciar o processo de } \\
\text { deterioração do material? } \\
\text { (Apresentar justificativa com base em norma técnica) }\end{array}$} \\
\hline \multicolumn{3}{|l|}{$\begin{array}{l}\text { Qual o impacto físico para a instalação do elemento feito deste } \\
\text { material? } \\
\text { (Apresentar justificativa com base em norma técnica) }\end{array}$} \\
\hline \multicolumn{3}{|l|}{$\begin{array}{l}\text { Qual o impacto físico para a desinstalação do elemento feito } \\
\text { deste material? } \\
\text { (Apresentar justificativa com base em norma técnica) }\end{array}$} \\
\hline \multicolumn{3}{|l|}{ PERCEPÇÃO DO VISITANTE } \\
\hline \multicolumn{3}{|l|}{ Possui brilho? } \\
\hline \multicolumn{3}{|l|}{ Reflete sob a incidência de luz? } \\
\hline \multicolumn{3}{|l|}{$\begin{array}{l}\text { Emite som metálico, ou outro que seja diferente dos sons da } \\
\text { própria caverna? }\end{array}$} \\
\hline $\begin{array}{l}\text { A dimensão do elemento e o local de instalação do elemento } \\
\text { pode gerar respostas positivas aos três itens anteriores? }\end{array}$ & & \\
\hline
\end{tabular}

Figura 4: Modelo proposto para a SubMatriz. Fonte: elaborado pelos autores.

Figure 4:Model proposed for Submatrix. Source: authors.

\section{Considerações finais}

O SGI-IEF trouxe uma proposta inovadora baseada em princípios internacionais, cujas premissas são recomendadas por instituições como a IUCN, ABNT e ISO. Ao propor estratégias que envolvem o manejo adaptativo através da adequação de normas ISO, o SGI-IEF insere na discussão do manejo de cavernas turísticas em UCs os conceitos e procedimentos amplamente utilizados no setor privado, que vem garantindo 
um padrão de qualidade e redução de problemas ambientais em indústrias e serviços de diversos setores e portes.

Dado o caráter adaptativo do SGI-IEF, o próprio sistema pode e deve passar por revisões, a fim de promover a melhoria contínua. Assim, o Sistema ainda pode englobar outras temáticas que não foram exploradas nesta pesquisa como, por exemplo, a metodologia de análise de risco para o visitante.

O SGI-IEF ainda pode influenciar a elaboração dos Termos de Referência para PMEs, visto que coloca os Programas de Gestão como Política Ambiental e de Qualidade. Neste contexto, os Programas de Gestão se tornam um requisito mandatário que definem a orientação de todo o sistema. Assim, os Programas de Gestão devem considerar todos os elementos da cadeia produtiva que envolve a gestão de cavernas. Com isso, conclui-se que o SGI-IEF tem grande potencial de influenciar políticas públicas, visto que aborda uma nova ideologia para o manejo de cavernas turísticas em Unidades de Conservação.

\section{Referências}

ALMEIDA, C.M.V.B.; GIANNETTI, B.F. Ecologia industrial. São Paulo: Edgard Blücher, 2012. 109p.

ASSOCIAÇÃO BRASILEIRA DE NORMAS TÉCNICAS. NBR ISO 26000: Diretrizes sobre responsabilidade social. Rio de Janeiro, 2010.

ASSOCIAÇÃO BRASILEIRA DE NORMAS TÉCNICAS. NBR ISO 9001: Sistema de Gestão de Qualidade - Requisitos. Rio de Janeiro, 2015a.

ASSOCIAÇÃO BRASILEIRA DE NORMAS TÉCNICAS. NBR ISO 14001: Sistema de Gestão Ambiental - Requisitos com orientação de uso. Rio de Janeiro, 2015b.

BOGGIANI, P. C. et al. Definição de capacidade de carga turística das cavernas do Monumento Natural Gruta do Lago Azul (Bonito, MS). Geociências, v. 26, n.4. p.333-348, 2007.

BORRINI-FEYERABEND, G., N.; DUDLEY, T.; JAEGER, B.; LASSEN, N.; PATHAK BROOME, A.; PHILLIPS, T.; SANDWITH. Governança de Áreas Protegidas: da compreensão à ação. Série Diretrizes para melhores Práticas para Áreas Protegidas, No. 20, Gland, Suiça: UICN. xvi, 124p. 2017

BORSANELLI, F.A.; LOBO, H.A.S. Impactos causados à comunidade local com o fechamento das cavernas turísticas do PETAR em 2008 na visão dos stakeholders envolvidos. In: RASTEIRO, M.A.; SALLUN FILHO, W. (orgs.) Congresso Brasileiro de Espeleologia, 33, 2015. Eldorado. Anais... Campinas: SBE, 2015. p.719-727.

BRASIL. Constituição da República Federativa do Brasil. Brasília, DF: Senado Federal: Centro Gráfico, 1988. 292 p. 
BRASIL. Lei no 9.985, de 18 de julho de 2000. Regulamenta 0 art. 225, § 1o, incisos I, II, III e VII da Constituição Federal, institui o Sistema Nacional de Unidades de Conservação da Natureza e dá outras providências. Publicação DOU: 19 de julho de 2000.

BRASIL. Resolução CONAMA n. 347 de 10 de setembro de 2004. Dispõe sobre a proteção do patrimônio espeleológico. CONSELHO NACIONAL DO MEIO AMBIENTE - CONAMA. Publicação DOU: 13 de setembro de 2004.

CROXTON K. L. et al. The Demand Management Process. In: LAMBERT, D. M. Supply chain management: processes, partnerships, performance. Florida: Supply Chain Management Institute, p. 87-104, 2008.

FERREIRA, A.R.R.; LOBO, H.A.S.; PERINOTTO, J.A.J. Inventory and Quantification of Geosites in the State Tourist Park of Alto Ribeira (PETAR, São Paulo State, Brazil). Geoheritage, v.11, p.783-792, 2018.

FORD D.; WILLIAMS P. Karst hydrogeology and geomorphology. John Wiley \& Sons, Chichester, 2007. 578 p.

GARCIA, M.G. et al. The Inventory of Geological Heritage of the State of São Paulo, Brazil: Methodological Basis, Results and Perspectives. Geoheritage. n.10, p. 239-258, 2018.

GILLIESON, D. S. Management of caves. In BEYNEN. Philip E van (org). Karst Management. Springer, Netherlands, 2011.p. 141-158.

ISAIA, G. C. Materiais de Construção Civil e Princípios de Ciência e Engenharia de Materiais. Editora IBRACON, 3o ed. São Paulo, 2017. Volume1. $1760 \mathrm{p}$.

KARMANN, I.; FERRARI, J.A. Carste e cavernas do Parque Estadual Turístico do Alto Ribeira (PETAR), SP. In: SCHOBBENHAUS, C.; CAMPOS, D.A.; QUEIROZ, E.T.; WINGE,M.; BERBERT-BORN, M.L.C. (Orgs.) Sítios geológicos e paleontológicos do Brasil. 1.ed. Brasilia: DNPM/CPRM Comissão Brasileira de Sítios Geológicos e Paleobiológicos (SIGEP), 2002. p.401-413.

KARMANN, I.; SANCHEZ, L. E. Distribuição das rochas carbonáticas e províncias espeleológicas do Brasil. Espeleo-Tema, v. 13, p. 105-167, 1979.

KRAVCHENKO, G. A. et al. Aplicação de princípios da ecologia industrial nas empresas moveleiras de Goiás. Revista Engenharia Sanitária e Ambiental. vol.21 no.2 Rio de Janeiro, Apr./June 2016.

LOBO, H. A. S.; SCALEANTE, J. A. B.; RASTEIRO, M. A. ; CAMARGO, T. C. R.;:ZAGO, S.; SANTOS, V. Método para a classificação do grau de dificuldade em roteiros espeleoturísticos. Congresso Brasileiro de Espeleologia, 31, 2011. Ponta Grossa - PR. Anais 31을 de 21-24 de julho de 2011. Ponta Grossa: CBE, 2011. p. 181-188. Disponível em: $<$ http://www.cavernas.org.br/anais31cbe/31cbe 181-188.pdf>. Acesso em: 04/11/2018

MARRA, R.J.C. Espeleo turismo: planejamento e manejo de cavernas. Brasília: WD Ambiental, 2001. 224 p. 
SÃO PAULO (Estado). Fundação Para a Conservação e a Produção Florestal do Estado de São Paulo. Plano de Manejo Espeleológico do Parque Estadual Intervales. São Paulo. 2014a.

SÃO PAULO (Estado). Fundação Para a Conservação e a Produção Florestal do Estado de São Paulo. Plano de Manejo Espeleológico do Parque Estadual Turístico do Alto Ribeira. São Paulo. 2014b

SÃO PAULO (Estado). Fundação Para a Conservação e a Produção Florestal do Estado de São Paulo. Plano de Manejo Espeleológico do Parque Estadual do Rio Turvo. São Paulo. 2014c.

SÃO PAULO (Estado). Fundação Para a Conservação e a Produção Florestal do Estado de São Paulo. Plano de Manejo Espeleológico do Parque Estadual da caverna do Diabo. São Paulo. 2014d.

SÃO PAULO (Estado). Fundação Para a Conservação e a Produção Florestal do Estado de São Paulo. Termo de Referência para contratação de serviço especializado em espeleologia, objetivando garantir excelência técnica para subsidiar a implantação de estruturas no interior de cavernas. São Paulo. 2015 (documento interno).

SILVERIO, M. O. Atuação da arquitetura no uso público das cavernas: conceitos, métodos e estratégias para ocupação: Cavernas do Diabo/SP, 2014. 255 f. Dissertação (Mestrado em Projeto de Arquitetura: teoria e método) Faculdade de Arquitetura e Urbanismo da Universidade de São Paulo. São Paulo, 2014.

TRAJANO, E.; BICHUETTE. M.E. Biologia subterrânea: Introdução. São Paulo: Redespeleo, 2006. 92p

Blanche Sousa Levenhagen: Universidade Federal de São Carlos, Sorocaba, SP, Brasil.

E-mail: blanche@ecobioconsultoria.com.br

Link para o currículo Lattes: http://lattes.cnpq.br/0362793301677527

Heros Augusto Santos Lobo: Universidade Federal de São Carlos, Sorocaba, SP, Brasil.

E-mail: heroslobo@ufscar.br

Link para o currículo Lattes: http://lattes.cnpq.br/9405961078398915

Data de submissão: 29 de maio de 2019

Data de recebimento de correções: 07 de julho de 2020

Data do aceite: 07 de julho de 2020

Avaliado anonimamente 